\title{
Research on Industrialization of Electric Vehicles with its Demand Forecast Using Exponential Smoothing Method
}

\author{
Zhanglin Peng, Zhijun Yu, Hongbo Wang, Shanlin Yang \\ School of Management, Hefei University of Technology (China) \\ pengzhanglin@163.com,_bijuny88@mail.bfut.edu.cn,bz308cctv@163.com,bgdjangshanlin@163.com
}

Received: October 2014

Accepted: February 2015

\section{Abstract:}

Purpose: Electric vehicles industry has gotten a rapid development in the world, especially in the developed countries, but still has a gap among different countries or regions. The advanced industrialization experiences of the EVs in the developed countries will have a great helpful for the development of EVs industrialization in the developing countries. This paper seeks to research the industrialization path \& prospect of American EVs by forecasting electric vehicles demand and its proportion to the whole car sales based on the historical 37 EVs monthly sales and Cars monthly sales spanning from Dec. 2010 to Dec. 2013, and find out the key measurements to help Chinese government and automobile enterprises to promote Chinese EVs industrialization.

Design/methodology/approach: Compared with Single Exponential Smoothing method and Double Exponential Smoothing method, Triple exponential smoothing method is improved and applied in this study.

Findings: The research results show that: (1) American EVs industry will keep a sustained growth in the next 3 months. (2) Price of the EVs, price of fossil oil, number of charging station, EVs technology and the government market \& taxation polices have a different influence to EVs sales. So EVs manufacturers and policy-makers can adjust or reformulatesome technology tactics and market measurements according to the forecast 
results. And (3) China can learn from American EVs polices and measurements to develop Chinese EVs industry.

Originality/value: The main contribution of this paper is to use the triple exponential smoothing method to forecast the electric vehicles demand and its proportion to the whole automobile sales, and analyze the industrial development of Chinese electric vehicles by American EVs industry.

Keywords: electric vehicles, market demand, forecast, exponential smoothing method

\section{Background of International Electric Vehicles Industry}

Harvard Kennedy School (2011) has reported there may be as many as 1.5 billion cars on the road by 2050 , compared to 750 million in 2010. The growth of demand represents both an opportunity and a challenge on new vehicles technologies, that is, Electric Vehicles (EVs) is just one of New Energy Vehicles. IEDC (International Economic Development Council, 2013) has reported that EVs industry create additional economic development opportunities by improving quality of life, reducing energy spending, and decreasing reliance on foreign oil.

In order to solve the energy, environmental constraints and achieve sustainable development, the world auto industry has long been in active exploration to promote the transformation of transport energy power system. Especially since the year of 2008, in the face of financial crisis, high international oil price shocks and increasingly severe pressure on energy-saving and emission reduction, the world automobile industry entered the transformation period of transportation energy, the development of electric vehicles becomes the technical route of transportation energy transformation that become an international consensus.

The world electric vehicles industry has entered a new stage of accelerated development. Many countries has taken many polices and measurement to develop their EVs industry. Firstly, the national governments have issued the development strategy and national plan of electric vehicles, which further points out the direction of industrial development. Japanese government take the development of electric vehicles as the core content of "low carbon revolution", and try to the make the usage quantity of "the next generation of automobiles", including electric vehicles, reach 1.35 million. In November 2008, the German government put forward promoting the use of 1 million pure electric vehicles and plug-in hybrid vehicles in the next 10 years, and claimed that the implementation of this plan marked Germany would enter the electric vehicles era. America government implement Green New Deal, among which the electric vehicles are considered as an important part of national strategy, and plan to popularize the use of 1 million hybrid electric vehicles by 2015 . The implement of national 
strategy has an important guiding role on industry development and will certainly further accelerate the development process of international electric vehicle industry. After 2000, Chinese government has presented Series of policies to push EVs industry development, such as 863 major projects of Electric vehicle R\&D and industrialization (Jan. 2001), Automobile industry restructuring and revitalization plan (Mar. 2009), Notice on the private purchase of new energy vehicles subsidy pilot (Jun. 2010) and Energy-saving and new energy automotive industry development plan (2010 - 2012). Secondly, power battery has received considerable attentions, $R \& D$ investment has increased dramatically, and the breakthrough of electric vehicle technology is expected to greatly enhance. Before 2011, the Japanese government had invested about 40 billion yen for advanced battery technology research. Since 2011, Germany government launched a vehicle development program about lithium battery, which almost all German automotive and energy giants have joined. In August 2009, Obama, the USA president, announced to pay out $\$ 2$ billion to support advanced battery R\&D and its industrialization. Thirdly, the national governments increase policy support and promote the industrialization of electric vehicles with all strength. On the one hand, the government increases the policy incentives for consumers to speed up the market growth of electric vehicles. In April 2009, Japan began to implement a new green tax, which means that pure electric vehicles, hybrid vehicles and other vehicles with low emission and low fuel consumption are given tax preference. At about the same time, the British government introduced new vehicle excise duty, while pure electric vehicles are exempt from consumption tax. The French government gives the highest award of 5000 Euros to consumers who purchase low-emission vehicles. America is slightly different, the government implements preferential taxation on PHEV, and the tax deductibility ranges from $\$ 2500$ and $\$ 15000$. On the other hand, the government encourages enterprises to speed up the industrialization of electric vehicles by increasing credit support. American government provides loans for the production of electric vehicles. Now, the international EVs industry has a very great development opportunity.

Eberle and von Helmolt (2010) pointed that about $96 \%$ of the fuel used for propulsion purposed is thereby produced from fossil sources of energy. With the increase of the vehicles, global crude oil demand and worldwide $\mathrm{CO} 2$ emissions will be inevitably increased, which are unsustainable for financial, ecological and political reasons. In order to reduce the dependence on fossil fuels and $\mathrm{CO} 2$ emissions, electric vehicles (EVs) and Plug-in Hybrid Electric Vehicles (PHEVs), and other new energy vehicles are developed, introduced and sold in the automobile market. Uses of EVs (such as Leaf, Smart ED, Mitsubishi I EV, BMW Active E, Ford Focus, Honda Fit EV, Tesla Model S*, RAV4 EV) and PHEVs (such as Volt, Prius PHEV, Ford C-Max, Honda Accord, Ford Fusion Energi) maintain rapid growth in recent years, and are expected to rise considerably in the near future in many developed countries and large developing countries around the world (Alizadeh, Scaglione, Davies \& Kurani, 2014; Axsen, Kurani, McCarthy \& Yang, 2011), with more and more incentive polices to new energy automobile 
industry are made by main industrial countries and the EVs and PHEVs technique are developed by many leading automobile manufacturers (Li \& Zhang, 2012). From the website of U.S. Department of Energy, we can see that US monthly EVs sales shattered the 10,000 unit barrier, which was reported on September 5, 2013, and a 30\% increase over the previous monthly record and a $75 \%$ increase since the same time last year were estimated. Successive months of $10,000+$ sales would put the U.S. burgeoning EVs and PHEVs market on track to double sales from 2012 to 2013, which researched by U.S. Department of Energy (2013a). For simplicity, EVs, PHEVs, and any other E-drive vehicles are collectively referred to Electric Vehicles (EVs) in this study.

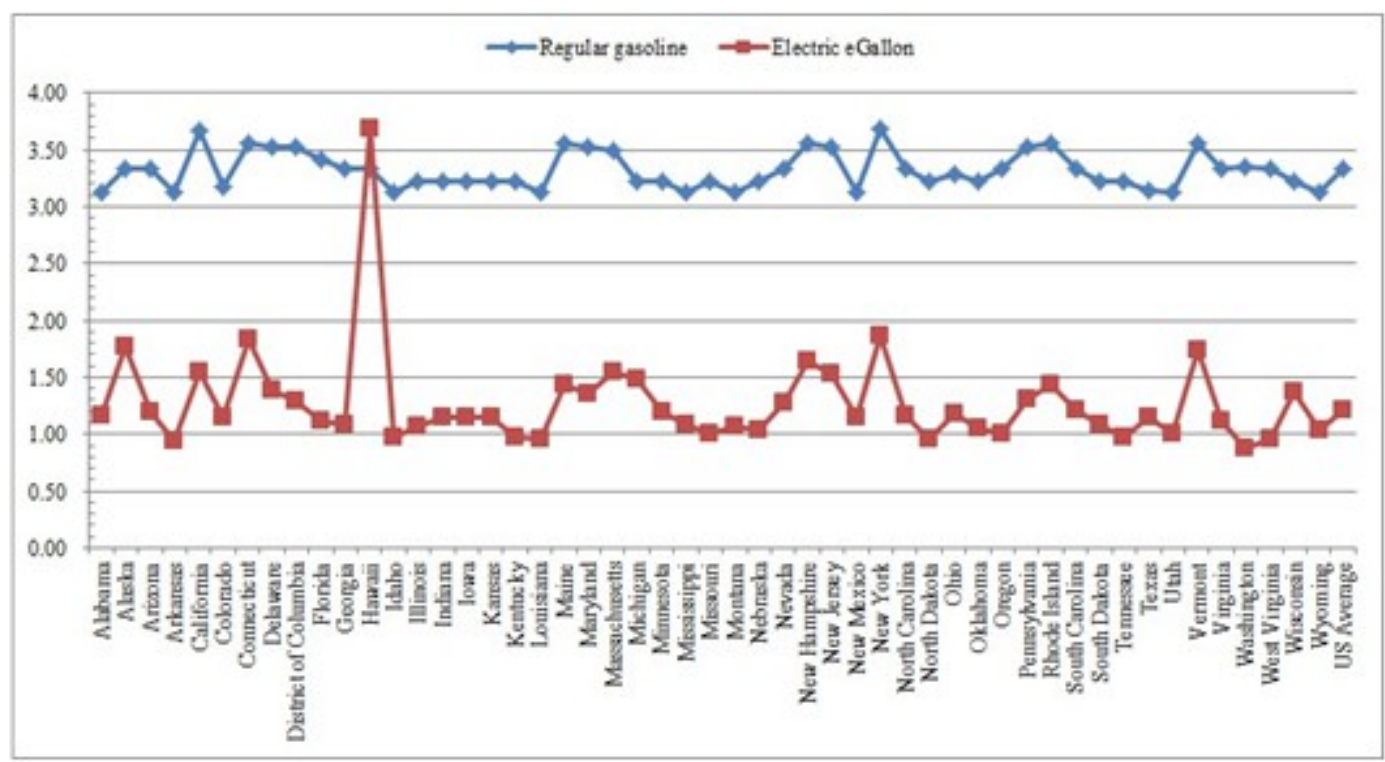

Figure 1. The unit prices of regular gasoline and electric eGallon in 50 states and 1 district in USA. Data was collected from the official website of US Department of Energy on March, 11, 2014 (http://energy.gov/articles/ev-sales-skyrocketing-egallon-holds-steady)

As we know, EVs take advantages of their high energy efficiency and low off-gas emission compared to conventional internal combustion engine based vehicles (Li \& Zhang, 2012). The EVs is an effective way for reducing energy consumption, especially reducing fossil fuel consumption. Balducci (2008) pointed that a PHEV with a 30-mile range would enable an average of $60 \%$ of the motoring public to entirely avoid motor fuel consumption each day based on American travel profiles (Raskin \& Shah, 2006). The U.S. Department of Energy compares the EVs cost to commute to drive with that of the traditional car by taking the average distance that a gasoline-powered vehicle can drive on a gallon of gas (28.2 miles for comparable 2012 model year cars), then the test results show that fuelling car with gasoline costs roughly 3 times more than fueling with electricity, on average researched by U.S. Department of Energy (2013b). Figure 1 gives the regular gasoline price and electric eGallon 
price in 50 states and 1 district in USA. Gasoline price is significant higher than electric eGallon in American states or districts, except Hawaii. On average, gasoline price is 2.75 times of electric eGallon price. The low carbon profile of EVs is also attractive for many governments and consumers. The application and promotion of EVs reduce automobile fossil fuel consumption and exhaust gases, which benefits the environment in our world.

\section{Research Framework and Purposes}

With respect to the developing EVs technology and the increasing sales, the percentage of EVs sales to Cars sales is still very low. Many consumers still take a wait-and-see attitude, and are careful to purchase EVs. Up until now, it's just a start for EVs industry. We believe that EVs will be developed better and its proportion to Cars sales will be increased in the future, and it's likely to replace the traditional cars with internal combustion engine. But there are so many barriers to develop EVs. EVs sales and market demands are also influenced and determined by many factors, such as the economic drivers, technology constraints, market potential, government policies, etc. If we can identify these influence factors and find out how they influence and determine the EVs sales and demands, on one hand, the government or the automobile industry can manage and control the whole EVs market sales and demand in their own countries, on the other hand, the EVs manufacturer can also control their own shares in the EVs market.

Our researches are mainly focused on the relationship between EVs demand and influence factors including internal and external variables, and how these factors influence EVs demand. And we further study that how the government and EVs manufacturer to control EVs sales and its demand by changing one or more factors. In our research, we use American EVs industry as the sample, due to its better EVs market and more collected data than any other countries in the world. The research is a complicated work, because some of these influence factors can be measured and tracked, but some of them are difficult to measure and track. In order to achieve our research purposes, we decompose our whole research into 4 parts:

- Part 1: We fit the observation data and forecast the future EVs demand based on the historical sales data using forecast methods. In this study, we collect 37 EVs monthly sales and 37 Cars monthly sales from Dec. 2010 to Dec. 2013.

- Part 2: We will find out the influence factors that can be measured and tracked, such as monthly price of electric eGallon, monthly price of regular gasoline, monthly price of EVs, monthly price of other Cars (not include EVs), monthly amount of fast charging stations across the USA, each EV's maximum miles driven to gallons of fuel saved, government subsidy for purchasing EVs. And we will further find out the relationships among the US EVs sales and these factors by means of regression equation. 
- Part 3: Based on the research results form Part 1 and Part 2, we will continue to deduce those unmeasured influence factors and their contributions to US EVs sales. Those unmeasured factors mainly include government macro-policies, vehicle dependability, battery reliability, automotive design, supply chain management, EVs security, consumer behavior, enterprise strategy and the global economy.

- Part 4: According to the previous 3 Parts, we can clearly estimate and fit the relationships among the EVs monthly sales and all influence factors using the benchmark data. Then we would easily know how each factor influences EVs sales, and the manufacturers can forecast the future EVs demands or sales, once one or more factors will be changed or adjusted by the governments or the EVs companies.

Our whole research devotes to work out the linear and non-linear relationships among the EV sales and those factors, and wants to find out the key factors which influence on the EV sales most. Forecast method, regression model and sensitivity analysis will be applied. We hope our research maybe give the EV enterprises or the EV industry some specific suggestions to adjust their market measurements or technological tactics to improve EV sales in practice. For this paper, it's just the research context and the findings referring to Part 1 . We will forecast the future electric vehicles demand based on the historical benchmark sales data during the period studied in USA, in order to see American EVs demand trends and its proportion to the whole automobile industry in the next few months.

In recent years, several methods have been proposed to model and forecast product demand, such as Bayesian Model (Lee, Lee \& Lee, 2012; Pezzulli et al., 2006), Neural Network (Tilokavichai \& Sophatsathit, 2011; Lau, Ho \& Zhao, 2013; Singhal \& Swarup, 2011; Yu \& Huarng, 2010), Times Series Analysis (Box, Jenkins \& Reinsel, 2013; Hunt \& Amarawickrama, 2008; Zhang, Huang \& Zhao, 2013), Grey Theory (Yao, Chi \& Chen, 2003; Hsu \& Chen, 2003) Genetic Algorithm (Haldenbilen \& Ceylan, 2005) and so on. Exponential Smoothing Method (ESM) is often considered to apply for building forecasting model, which is developed by Robert G. Brown (Brown \& Meyer, 1961). Brown also pointed that ESM is a formalization of the familiar learning process, which is a practical basis for statistical forecasting. We also know that the smoothing computations are very simple, and only a minimum of historical statistics need to be retained from one forecast to the next (Brown \& Meyer, 1961). In this study, we apply ESM to forecast the future US EVs demand based on the historical statistic data.

\section{The Principle of Exponential Smoothing Method}

Exponential Smoothing Method (ESM) is a popular scheme to produce a smoothed time series (Pyo \& Choi, 2009). Whereas in moving averages the past observations are weighted equally, exponentially increasing weights are assigned as the observation gets latter. That is, recent 
observations are given more weight than the older ones in forecasting. Single Exponential Smoothing (SES), Double Exponential Smoothing (DES) and Triple Exponential Smoothing (TES) are three typical principles of ESM as follows.

\subsection{Single Exponential Smoothing}

Single Exponential Smoothing (SES) is the simplest scheme in ESM and is used for data displaying a horizontal pattern. SES is just suitable for time series data with stationary characteristic rather than the data with drastic increase or decrease. The following are some basic equations.

$$
Y_{t+1}=Y_{t}+\alpha\left(X_{t}-Y_{t}\right)
$$

where $X_{t}, Y_{t}$ are actual value and prediction value at time $t$, and $\alpha$ is a smoothing coefficient varying between 0 and 1 supplied by the researcher.

SES requires the researcher to specify the initial value and the smoothing coefficient $\alpha$, which remains fixed throughout the entire forecasting procedure. However, SES is adaptive because it allows the value of $\alpha$ to change automatically as a result of changes in the data patterns. Equation 2 to 6 are used to compute using this model:

$$
\begin{gathered}
Y_{t+1}=\alpha_{t} X_{t}+\left(1-\alpha_{t}\right) Y_{t} \\
\alpha_{t+1}=\left|E_{t} / M_{t}\right| \\
E_{t}=\beta\left|e_{t}\right|+(1-\beta) E_{t-1} \\
M_{t}=\beta\left|e_{t}\right|+(1-\beta) M_{t-1} \\
e_{t}=X_{t}-Y_{t}
\end{gathered}
$$

where $e_{t}$ is the prediction error corresponding to time $t, \alpha_{t}$ and $\beta$ are smoothing coefficient varying between 0 and $1, E_{t}$ is a smoothed error term, and $M_{t}$ is a smoothed absolute error term. $E_{1}, M_{1}, \alpha$ and $\beta$ are specified. 


\subsection{Double Exponential Smoothing}

Double Exponential Smoothing (DES) is used to get the forecast for a time series displaying a trend pattern. It can be thought as a once more single exponential smoothing based on SES. If $X_{t}$ represents an observation at time $t, S_{1, t}$ is the first exponential smoothing, and $S_{2, t}$ is the second exponential smoothing, then the forecast value at time $t$ can be calculated by Equation 7 to 11 .

$$
\begin{gathered}
S_{1, t}=\alpha X_{t}+(1-\alpha) S_{1, t-1} \\
S_{2, t}=\alpha S_{1, t}+(1-\alpha) S_{2, t-1} \\
a_{t}=2 S_{1, t}+S_{2, t} \\
b_{t}=\alpha /(1-\alpha)\left(S_{1, t}+S_{2, t}\right) \\
Y_{t+m}=a_{t}+m b_{t}
\end{gathered}
$$

where $\alpha$ is a smoothing coefficient, $S_{1, t}$ and $S_{2, t}$ are also specified.

\subsection{Triple Exponential Smoothing}

Triple Exponential Smoothing (TES) means that one more smoothing is given after the smoothing by DES. In essence, it is a quadratic polynomial exponential smoothing presented by Robert G. Brown (Brown \& Meyer, 1961), which is transferred from linear exponential smoothing to non-linear quadratic polynomial exponential smoothing method. It devotes to fit and track the change trend data based on the historical statistics. Some basic equations are as followed.

$$
Y_{t+T}=a_{t}+b_{t} T+c_{t} T^{2}
$$

where

$$
\begin{gathered}
a_{t}=3 S_{t}^{(1)}-3 S_{t}^{(2)}+S_{t}^{(3)} \\
b_{t}=\frac{\alpha}{2(1-\alpha)}\left[(6-5 \alpha) S_{t}^{(1)}-2(5-4 \alpha) S_{t}^{(2)}+(4-3 \alpha) S_{t}^{(3)}\right]
\end{gathered}
$$




$$
c_{t}=\frac{\alpha^{2}}{2(1-\alpha)^{2}}\left(S_{t}^{(1)}-2 S_{t}^{(2)}+S_{t}^{(3)}\right)
$$

The smoothing equations are as followed:

$$
\begin{gathered}
S_{t}^{(1)}=\alpha X_{t}+(1-\alpha) S_{t-1}^{(1)}=\alpha X_{t}+\alpha(1-\alpha) X_{t-1} \ldots+\alpha(1-\alpha)^{t-1} X_{1} \\
S_{t}^{(2)}=\alpha S_{t}^{(1)}+(1-\alpha) S_{t-1}^{(2)} \\
S_{t}^{(3)}=\alpha S_{t}^{(2)}+(1-\alpha) S_{t-1}^{(3)}
\end{gathered}
$$

where $X_{t}$ is the actual value for time $t, S_{t}$ is the smoothed value for time $t, S_{t}^{(1)}$ is the first smoothing value for time $t, S_{t}^{(2)}$ is the second smoothing value for time $t$, and $S_{t}^{(3)}$ is the third smoothing value for time $t$. $\alpha$ is a constant that must be estimated in such a way that the MSE of the error is minimized. And they are between 0 and 1 .

In conclusion, we can easily get that:

- The prediction value using SES is just the weighted average of actual series data. Thus, SES is suitable for time series data with stationary characteristic rather than the data with drastic increase or decrease. SES is better at dealing with trends without nonseasonal feature;

- DES is used to obtain the forecasts for a time series displaying a trend pattern, in other words, it is better at dealing with trends. Generally, DES is used to calculate the coefficient in the linear equations, rather than directly fit time series data; and

- when the distribution of observation values presents the curvature, which maybe indicates the relationship between the independent variable and dependent variable is nonlinear. In this case, TES is better than DES and SES to carry out forecast.

\section{Forecasting the Electric Vehicles Demand Using Triple Exponential Smoothing}

\subsection{The Source of the Statistic Data}

In this study, American EVs monthly sales and American Cars monthly sales spanning from Dec. 2010 to Dec. 2013 are collected from the websites of Argonne National Laboratory and of U.S. Department of Energy. The purpose of this study is to forecast EVs demand and its proportion to Cars demand in the next few months in USA. Therefore, we just need the past EVs monthly sales and past Cars monthly sales according to exponential smoothing method. 
Table 1 gives 37 EVs monthly sales and Cars sales during the period studied, which are represented by $X^{1}$ and $X^{2}$, respectively.

\begin{tabular}{|c|c|c|c|c|c|c|c|c|}
\hline Month & $\begin{array}{c}\text { EVs Sales } \\
\left(X^{1}\right)\end{array}$ & $\begin{array}{c}\text { Cars Sales } \\
\left(X^{2}\right)\end{array}$ & Month & $\begin{array}{c}\text { EVs Sales } \\
\left(X^{1}\right)\end{array}$ & $\begin{array}{c}\text { Cars Sales } \\
\left(X^{2}\right)\end{array}$ & Month & $\begin{array}{c}\text { EVs Sales } \\
\left(X^{1}\right)\end{array}$ & $\begin{array}{c}\text { Cars Sales } \\
\left(X^{2}\right)\end{array}$ \\
\hline Dec-10 & 345 & 540,511 & Jan-12 & 1,427 & 474,449 & Jan-13 & 4,726 & 538,991 \\
\hline Jan-11 & 424 & 406,662 & Feb-12 & 1,662 & 618,915 & Feb-13 & 5,455 & 617,492 \\
\hline Feb-11 & 364 & 508,787 & Mar-12 & 4,161 & 770,314 & Mar-13 & 7,632 & 759,172 \\
\hline Mar-11 & 906 & 674,753 & Apr-12 & 3,595 & 639,516 & Apr-13 & 7,138 & 654,659 \\
\hline Apr-11 & 1,066 & 627,442 & May-12 & 3,378 & 695,860 & May-13 & 7,754 & 727,587 \\
\hline May-11 & 1,631 & 561,484 & Jun-12 & 3,318 & 669,305 & Jun-13 & 8,742 & 709,455 \\
\hline Jun-11 & 2,269 & 536,782 & Jul-12 & 3,016 & 589,098 & Jul-13 & 7,442 & 657,195 \\
\hline Jul-11 & 1,057 & 517,918 & Aug-12 & 4,744 & 655,862 & Aug-13 & 11,363 & 751,943 \\
\hline Aug-11 & 1,665 & 519,230 & Sep-12 & 5,809 & 606,797 & Sep-13 & 8,127 & 566,676 \\
\hline Sep-11 & 1,754 & 495,620 & Oct-12 & 7,232 & 548,999 & Oct-13 & 10,100 & 578,378 \\
\hline Oct-11 & 1,974 & 489,083 & Nov-12 & 7,158 & 570,668 & Nov-13 & 8,833 & 597,790 \\
\hline Nov-11 & 1,912 & 470,383 & Dec-12 & 7,669 & 653,516 & Dec-13 & 9,790 & 631,085 \\
\hline Dec-11 & 2,741 & 571,719 & & & & & & \\
\hline
\end{tabular}

Table 1. EVs monthly sales and Cars sales from Dec. 2010 to Dec. 2013 in USA. Data was from Argonne National Laboratory and U.S. Department of Energy http://www.transportation.anl.gov/technology analysis/edrive vehicle monthly sales.html

\subsection{Computation and Results}

There are many quantitative forecast methods, thus, it needs to select a convenient, scientific and accurate method on the basis of the analysis to the historical data.

As you can see in Figure 2, the EVs historical monthly sales have changed great in past 3 years, especially after March 2012, which has gotten drastic increase. With regard to such historical data, SES and DES are obviously not suitable in this study. However, the TES method can not only fit curve fitting, but also have time-varying adaptability. Furthermore, it has asymptotic optimality under the condition of enough large samples. Therefore, it is very appropriate to use TES to forecast EVs monthly demand and its proportion to Cars sales in the next few months in USA. For the same reason, this approach is also used to forecast Cars monthly sales.

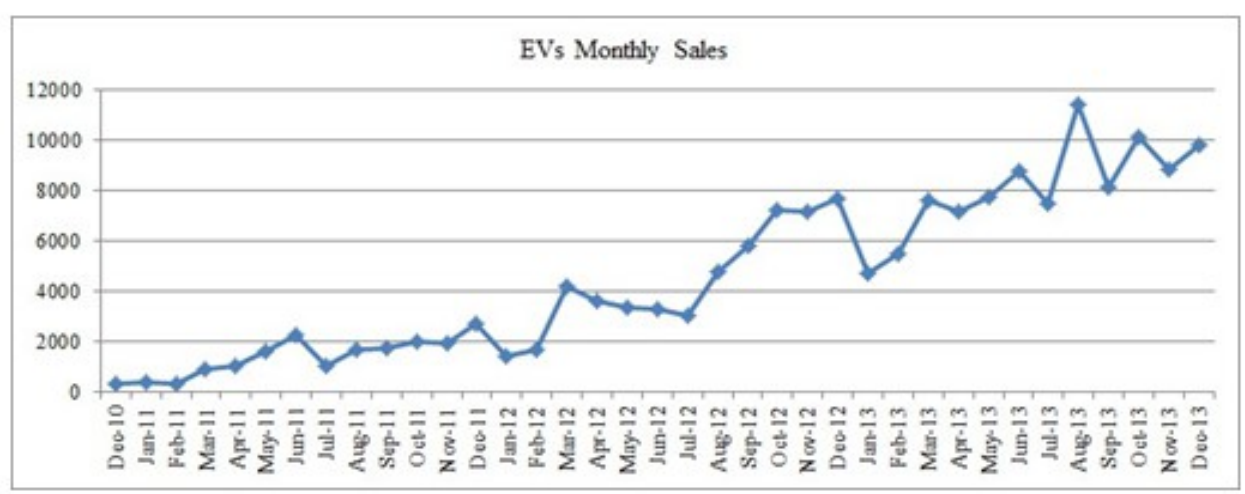

Figure 2. EVs monthly sales from Dec. 2010 to Dec. 2013 in USA 
According to TES, we give the following implementation steps:

\section{Step 1: Estimation of Exponential Smoothing Parameters}

We must firstly estimate the initial value of exponential smoothing parameters, when we do forecast using TES. The estimation of the initial value is very important for the value of the smoothing coefficient, which also determines the smoothing ability and the response time corresponding to the difference between the prediction value and the actual value. In this study, we determine the mean value of the earliest 3 month as the initial value of exponential smoothing parameters, that is,

$$
S_{0}^{(1)}=S_{0}^{(2)}=S_{0}^{(3)}=\frac{\left(X_{1}+X_{2}+X_{3}\right)}{3}
$$

\section{Step 2: Selection of the Smoothing Coefficient}

The smoothing coefficient $\alpha$ is a crucial parameter, which is more close to 1 , the descending trend on the longer observation values to the current smoothing values will be more rapid. On the contrary, $\alpha$ is more close to 0 , the descending trend will be slower. Therefore, when time series is relatively stable, $\alpha$ should get a bigger value, inversely, $\alpha$ should get a smaller one.

\section{Step 3: Implementation of Initial Prediction}

Generally, we use Minimum Squared Prediction Error (MSPE) to measure the accuracy of prediction, MSPE is smaller, and the accuracy of prediction is higher. On the contrary, MSPE is bigger, and the accuracy of prediction is lower. Certainly, we want to get the prediction value under the highest accuracy of prediction corresponding to the smallest MSPE. In order to get the Minimum Squared Prediction Error (MSPE), we should select some observations or samples to do initial prediction. We use different smoothing coefficient varying from 0 to 1 to get different series of prediction values. Then, we can calculate the MSPE by the following Equation 20.

$$
M S P E=\frac{1}{N} \sqrt{\sum_{i=1}^{N}\left[\left(X_{t}-Y_{t}\right) / X_{t}\right]^{2}}
$$




\section{Step 4: Forecasting the Future Demand under the Minimum MSPE}

Based on the above 3 steps and the historical sales data shown in Table 1, we use the Equation 12 to 18 to forecast the demand on EVs and Cars in USA, respectively.

According to the above 4 steps, we firstly use the mean value of the longest 3 month as the Equation 12 to 18 initial value of exponential smoothing parameter, that is because the data has more fluctuant in the earliest month. According to Equation 19, we get the initial value of exponential smoothing parameter is 378 and 48,5320 respectively referring to EVs monthly sales and Car monthly sales. Then we let $\alpha$ as $0.1,0.2,0.3,0.4,0.5,0.6,0.7,0.8$ and 0.9 . Finally, we use the earlier 34 months data of EVs sales and Cars sales spanning from Dec. 2010 to Sep. 2013 to forecast the recent 3 months market sales spanning from Oct. 2013 to Dec. 2013. Comparison the prediction value with the actual sales data, we get different MSPEs under different smoothing coefficients, which are shown in Table 2. Where $\operatorname{MSPE}\left(x^{1}\right)$ and $\operatorname{MSPE}\left(x^{2}\right)$ represents the prediction error of EVs and Car, respectively.

\begin{tabular}{|c|c|c|c|c|c|c|c|c|}
\hline$\alpha$ & $\operatorname{MSPE}\left(x^{1}\right)$ & $\operatorname{MSPE}\left(x^{2}\right)$ & $\alpha$ & $\operatorname{MSPE}\left(x^{1}\right)$ & $\operatorname{MSPE}\left(x^{2}\right)$ & $\alpha$ & $\operatorname{MSPE}\left(x^{1}\right)$ & $\operatorname{MSPE}\left(x^{2}\right)$ \\
\hline 0.1 & 0.0840 & 0.1178 & 0.4 & 0.2616 & 0.1623 & 0.7 & 0.8586 & 0.5206 \\
\hline 0.2 & 0.1175 & 0.1274 & 0.5 & 0.3867 & 0.2402 & 0.8 & 1.2616 & 0.7438 \\
\hline 0.3 & 0.1762 & 0.1325 & 0.6 & 0.5772 & 0.3576 & 0.9 & 1.8187 & 1.0430 \\
\hline
\end{tabular}

Table 2. $\operatorname{MSPE}\left(x^{1}\right)$ and $\operatorname{MSPE}\left(x^{2}\right)$ under different values of $\alpha$

Table 2 shows both $\operatorname{MSPE}\left(x^{1}\right)$ and $\operatorname{MSPE}\left(x^{2}\right)$ get the minimum value, when $\alpha$ is 0.1 , and they are 0.0840 and 0.1178 . Therefore, we let $\alpha=0.1$, when we predict the future 3 months' demand of EVs and Car in USA. According to Equation 12 to 15, and $\alpha=0.1$, we can use the total 37 monthly sales to predict the future 3 monthly sales.

Equation 12 to 15 are solved by Eviews 6.0, and was implemented on a Intel (R) Core (TM) i52540M CPU @ 2.60GHZ with 4.00G RAM. Firstly, we get both the prediction values of EVs monthly sales and those of Car monthly sales from Dec. 2010 to Mar. 2014 shown in Figure 2 and Figure 3. Then we get that EVs monthly sales reaches $11,222,11,136$ and 11,361 in Jan., Feb. and Mar. in 2014, and the Car monthly sales reaches 662,064, 641,793 and 637, 438 in Jan., Feb. and Mar. in 2014, respectively.

\begin{tabular}{|r|r|r|}
\hline Month & EVs Sales $\left(\mathbf{x}^{\mathbf{1}}\right)$ & Cars Sales $\left(\mathbf{x}^{\mathbf{2}}\right)$ \\
\hline Jan-14 & 11,222 & 662,064 \\
\hline Feb-14 & 11,136 & 641,793 \\
\hline Mar-14 & 11,361 & 637,438 \\
\hline
\end{tabular}

Table 3. The prediction values of EVs monthly sales and those of Car monthly sales from Jan. 2014 to Mar. 14 in USA 


\subsection{Results Analysis}

Figure 3 gives the actual value and the prediction value of EVs monthly sales, and two sets of Car monthly sales are shown in Figure 4. Although some prediction errors are inevitable, both predicted EVs monthly sales and predicted Car monthly sales well fit the dynamic demands of EVs and Cars sales according to the historical sales data. According to the actual values and prediction values in Figure 3, we can see that the EVs monthly sales has gotten the rapid growth increasing from 345 in Dec. 2010 to 9,790 in Dec. 2013, especially, in Aug. 2013, it has shattered the 10,000 unit barrier and reached 11,363 . We can also see that the EVs sales keep growing in the first 3 months in 2014. The forecast results show that EVs demand in Jan. 2014 is 2.37 times of in Jan. 2013, and is 26.47 times of in Jan. 2011. If U.S. government gives more and more incentive policies and measures, and Car companies develop more energy efficiency and more security EVs, we believe that EVs will have a better market prospect in USA.

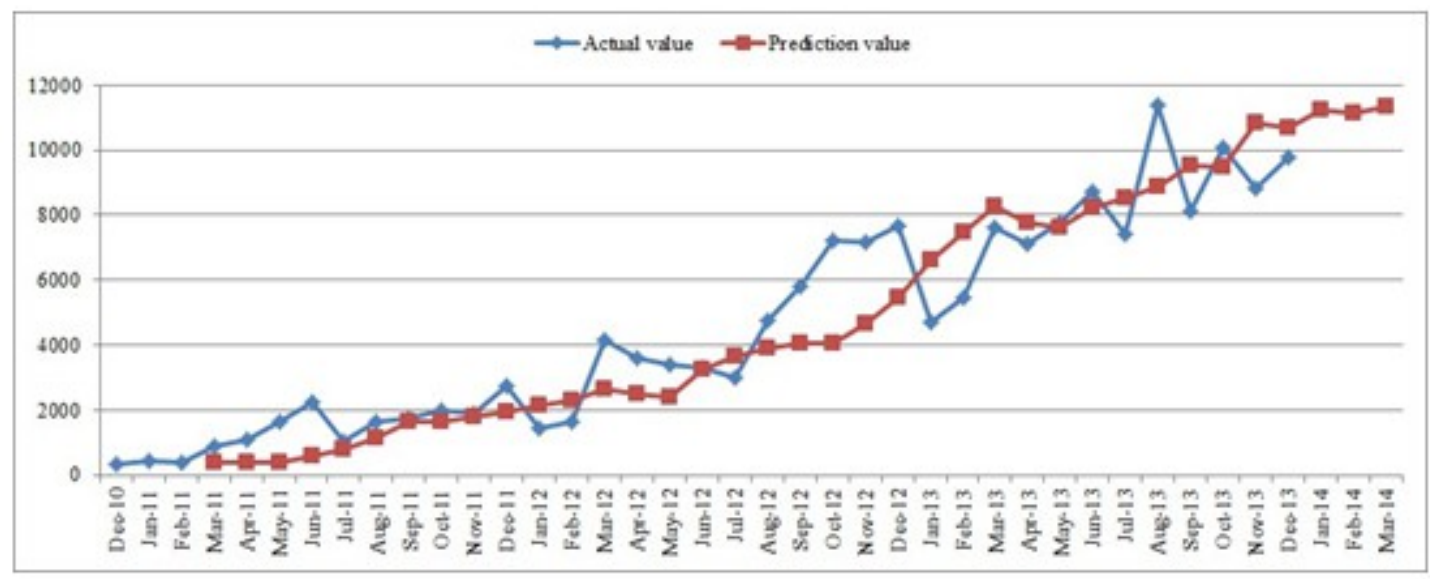

Figure 3. Prediction value of EVs monthly sales from Dec. 2010 to Mar. 2014

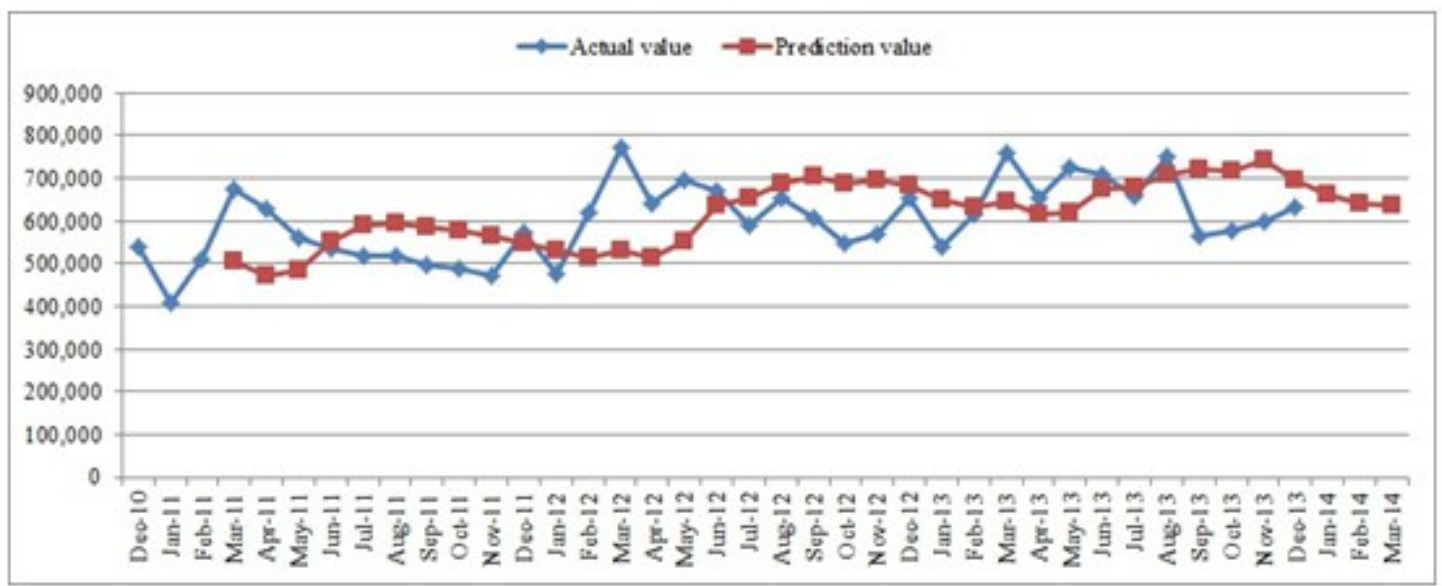

Figure 4. Prediction value of Car monthly sales from Dec. 2010 to Mar. 2014 
According to the data shown in Table 1, the prediction value of EVs monthly sales in the first 3 months in 2014 shown in Figure 3, and that of the Car monthly sales shown in Figure 4. We get the percentage of EVs monthly sales to Car monthly sales from Dec. 2010 to Mar. 2014, as it is shown in Figure 5. It shows that the percentage of EVs sales to Cars sales has gotten a steady growth in the past 3 years, with the increase from $0.06 \%$ in Dec. 2010 to $1.55 \%$ in Dec. 2013, and it reaches to $1.70 \%$ in Jan. 2014, 1.74\% in Feb. 2014, and $1.78 \%$ in Mar. 2014. It indicates that more and more Car consumers choose to purchase the EVs in recent years, under the government incentive policies and the EVs technology development. It would attain sustainable in the future months in USA.

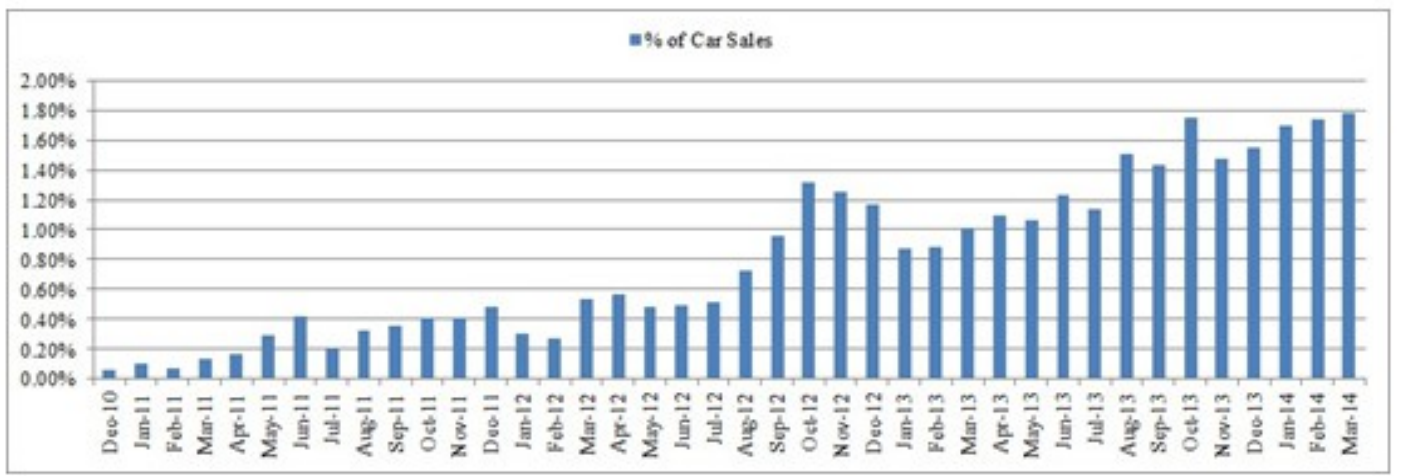

Figure 5. Percentage of EVs monthly sales to Car monthly sales from Dec. 2010 to Mar. 2014

In addition, by using 37 monthly sales to forecast, we calculate that MSPE of EVs monthly sales reaches to a level of $5.82 \%$ referring to TES method, $8.64 \%$ referring to SES method, and $20.10 \%$ referring to DES method. Under the TES method, the MSPE of EVs monthly sales is relatively low, therefore, the accuracy of prediction is relatively high. Then, we can easily get that TES method can get the better forecast result than SES method and DES method in this study.

More then, our research keeps the similar result with many famous institutions. For instance, Morgan Stanley predicts that, in 2020, the United States EVs car sales will reach 2 million, accounting for $13 \%$ of total light vehicle sales. Among them, the plug-in hybrid electric vehicle sales will reach 1 million. The cumulative sales of hybrid electric vehicle will reach 15 million by 2020, 3.7 million of which are plug-in electric vehicles. The American electric power research institute (EPRI) estimates that, by 2030 , plug-in electric vehicles will account for $40 \%$ of all light vehicles on the road, accounting for $50 \%$ of total light vehicle sales for that year. Therefore, what car firms have got to do is seize the opportunity and increase the investment to electric vehicles so as to win more market lot in the fury international market. Based on the above result analysis, we can see that EVs industry have a vast prospect, and the market demand of electric vehicle will continue to increase. And all relevant institutions in the United States are very bullish on the development of electric vehicles industry. 


\section{Conclusion and Discussion}

This study is one part of our whole research project, which devotes to work out the linear and non-linear relationship between the EV sales and the influence factors including some could be measured and others can't easily be measured, and seeks to find out the key factors which influence on the EVs sales most. The ultimate purpose is to give the EVs companies and the American government some specific suggestions to adjust their market and technological tactics or plans to improve EV sales in practice in their future EVs developments. This paper provides and effective solution, which can be used tightly observe and track the whole US EVs market demand based on the historical sales for EVs manufacturers and policy-makers.

We take the past 37 American EVs monthly sales and American Cars monthly sales as the samples. We forecast the electric vehicles demand and its proportion to the whole car industry in the first 3 months in 2014 using the historical benchmark sales data during the period studied in USA, in order to see American EVs demand trends in the next few months. The forecasting results show that: First, American EVs sales keep increasing in the first 3 months in 2014, and its demand in Jan. 2014 is 2.37 times of in Jan. 2013, and is 26.47 times of in Jan. 2011. Second, the percentage of EVs sales to Cars sales has gotten a steady growth in the past 3 years, with the increase from $0.06 \%$ in Dec. 2010 to $1.55 \%$ in Dec. 2013, and it reaches to $1.70 \%$ in Jan. 2014, $1.74 \%$ in Feb. 2014, and $1.78 \%$ in Mar. 2014. Third, the MSPE of EVs monthly sales reaches to a level of about $5.82 \%$ referring to TES method, about $8.64 \%$ referring to SES method, and about $20.10 \%$ referring to DES method, thus, TES get the lowest MSPE and the highest accuracy of prediction in this study. That is, TES is better than SES and DES in this research.

In our future research, the extension of this study has the following three research agendas according to our research plan: First, we continue to find out these influence factors that can be measured and tracked, and we further study on the relationship between the US EVs sales and these factors by means of regression equation. Second, we will continue to observe those unmeasured influence factors and their contributions to US EVs sales. Third, we seek to estimate and fit the relationship between the EVs monthly sales and all influence factors using the benchmark data. Finally, we will research on how the government and EVs manufacturer to make decision to improve their EVs market sales in different situations.

More importantly, the development of America electric vehicle industry has significant implications for Chinese EVs industry. First of all, we should emend and perfect the Energy Conservation Law of the People's Republic of China, and make clear the status of new energy vehicles and strategic objectives. Therefore, we suggest the government follow the U.S. energy policy options to make clear the strategic objectives of new energy vehicles, determine the developing goals, construct a time line of the development of new energy vehicles and specify the corresponding rights and rights of all levels of government. Second, Chinese government 
should make clear the key technologies of new energy vehicles and give strength support in financial policies and taxation polices, such as increasing subsidies for new energy vehicles purchases, reducing taxes and fees related to automobile consumption. All of these measurements will have a big positive power for developing the industrialization of Chinese EVs.

\section{Acknowledgments}

We are grateful to Yan (Joann) Zhou (yzhou@anl.gov) for some valuable suggestion and the latest EV sales in USA, who is a staff at Argonne National Laboratory. This research is supported by National Natural Science Foundation of China (NSFC) (Nos. 71131002, 71331002, and 71201043).

\section{References}

Alizadeh, M., Scaglione, A., Davies, J., \& Kurani, K.S. (2014). A Scalable Stochastic Model for the Electricity Demand of Electric and Plug-In Hybrid Vehicles. IEEE Transactions on Smart Grid, 5, 848-860. http://dx.doi.org/10.1109/TSG.2013.2275988

Axsen, J., Kurani, K.S., McCarthy, R., \& Yang, C. (2011). Plug-in hybrid vehicle GHG impacts in California: Integrating consumer-informed recharge profiles with an electricity-dispatch model. Energy Policy, 39, 1617-1629. http://dx.doi.org/10.1016/j.enpol.2010.12.038

Balducci, P.J. (2008). Plug-in Hybrid Electric Vehicle Market Penetration Scenarios. PNNL17441 Report. Pacific Northwest National Laboratory. Richland, WA. Available online in: http://www.pnl.gov/main/publications/ external/technical reports/pnnl-17441.pdf

Box, G.E., Jenkins, G.M., \& Reinsel, G.C. (2013). Time series analysis: forecasting and control. John Wiley \& Sons. Available online in:

http://books.google.com/books?hl=en\&lr=\&id=jyrCqMBW owC\&oi=fnd\&pg=PP1\&dq=time+series+analysis++ + forecast\&ots $=$ LPKOghJQO5\&sig $=\mid$ BqmYyoXp1JOH45fBHADLD-BjX4

Brown, R.G., \& Meyer, R.F. (1961). The Fundamental Theorem of Exponential Smoothing. Operations Research, 9, 673-685. http://dx.doi.org/10.1287/opre.9.5.673

Eberle, D.U., \& von Helmolt, D.R. (2010). Sustainable transportation based on electric vehicle concepts: a brief overview. Energy Environ Sci, 3, 689-699. http://dx.doi.org/10.1039/C001674H

Haldenbilen, S., \& Ceylan, H. (2005). Genetic algorithm approach to estimate transport energy demand in Turkey. Energy Policy, 33, 89-98. http://dx.doi.org/10.1016/S0301-4215(03)00202-7 
Harvard Kennedy School, Belfer Center for Science and International Affairs. (2011). Will Electric Cars Transform the U.S. Vehicle Market? An Analysis of the Key Determinants. Available online in: http://belfercenter.ksg.harvard.edu/files/Lee\%20Lovellette\%20Electric\%20Vehicles\%20DP \%202011\%20web.pdf

Hsu, C.-C., \& Chen, C.-Y. (2003). Applications of improved grey prediction model for power demand forecasting. Energy Conversion and Management, 44, 2241-2249. http://dx.doi.org/10.1016/S0196-8904(02)00248-0

Hunt, L.C., \& Amarawickrama, H.A. (2008). Electricity demand for Sri Lanka: a time series analysis. Energy, 33, 724-739.

International Economic Development Council (2013). Creating the Clean Energy Economy: Analysis of the Electric Vehicle Industry. Available online in:

http://www.iedconline.org/clientuploads/Downloads/edrp/IEDC_Electric_Vehicle_Industry.pdf

Lau, H.C.W., Ho, G.T.S., \& Zhao, Y. (2013). A demand forecast model using a combination of surrogate data analysis and optimal neural network approach. Decision Support Systems, 54, 1404-1416. http://dx.doi.org/10.1016/j.dss.2012.12.008

Lee, J., Lee, C.-Y., \& Lee, K.S. (2012). Forecasting demand for a newly introduced product using reservation price data and Bayesian updating. Technological Forecasting and Social Change, 79, 1280-1291. http://dx.doi.org/10.1016/j.techfore.2012.04.003

Li, G., \& Zhang, X.-P. (2012). Modeling of Plug-in Hybrid Electric Vehicle Charging Demand in Probabilistic Power Flow Calculations. IEEE Transactions on Smart Grid, 3, 492-499. http://dx.doi.org/10.1109/TSG.2011.2172643

Pezzulli, S. et al (2006). The seasonal forecast of electricity demand: a hierarchical Bayesian model with climatological weather generator. Appl Stochastic Models Bus Ind, 22, 113-125. http://dx.doi.org/10.1002/asmb.622

Pyo, S., \& Choi, Y. (2009). A fast handover scheme using exponential smoothing method. International Journal of Computer Science and Network Security, 9, 61-64.

Raskin, A., \& Shah, S. (2006). The Emergence of Hybrid Vehicles: Ending Oil's Stranglehold on Transportation and the Economy. Alliance Bernstein LP, New York, USA.

Singhal, D., \& Swarup, K.S. (2011). Electricity price forecasting using artificial neural networks. International Journal of Electrical Power \& Energy Systems, 33, 550-555. http://dx.doi.org/10.1016/j.ijepes.2010.12.009 
Tilokavichai, V., \& Sophatsathit, P. (2011). An organization-wide analysis of ERP and information systems interrelationship for logistics support. Journal of System and Management Sciences, 1(1), 59-68. Available online in:

http://pioneer.chula.ac.th/ sperapho/pub/JSMS issue 1.6.pdf

U.S. Department of Energy (2013a). Monthly EV Sales Shatter Records. Available online in: http://energy.gov/articles/monthly-ev-sales-shatter-records

U.S. Department of Energy (2013b). The eGallon: How Much Cheaper Is It to Drive on Electricity?. Available online in: http://energy.gov/articles/egallon-how-much-cheaper-it-drive-electricity

Yao, A.W.L., Chi, S.C., \& Chen, J.H. (2003). An improved Grey-based approach for electricity demand forecasting. Electric Power Systems Research, 67, 217-224. http://dx.doi.org/10.1016/S0378-7796(03)00112-3

Yu, T.H.-K., \& Huarng, K.-H. (2010). A neural network-based fuzzy time series model to improve forecasting. Expert Systems with Applications, 37, 3366-3372. http://dx.doi.org/10.1016/j.eswa.2009.10.013

Zhang, C., Huang, L., \& Zhao, Z. (2013). Research on combination forecast of port cargo throughput based on time series and causality analysis. Journal of Industrial Engineering and Management, 6(1), 124-134. http://dx.doi.org/10.3926/jiem.687

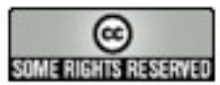

Article's contents are provided on a Attribution-Non Commercial 3.0 Creative commons license. Readers are allowed to copy, distribute and communicate article's contents, provided the author's and Journal of Industrial Engineering and Management's names are included. It must not be used for commercial purposes. To see the complete license contents, please visit http://creativecommons.org/licenses/by-nc/3.0/. 